\title{
Variations in patient-reported physical health between cardiac and musculoskeletal diseases: systematic review and meta-analysis of population-based studies
}

\author{
James A. Prior ${ }^{1 *}$, Kelvin P. Jordan ${ }^{1}$ and Umesh T. Kadam ${ }^{1,2}$
}

\begin{abstract}
Population-based assessments of physical health are important to evaluate healthcare resource allocation. Normative data on the level of physical impairments attributable to specific diseases and severity levels within these diseases is critical to interpreting such data. Our objective, by means of a systematic review and meta-analysis, was to test the hypothesis that specific diseases which form cardiovascular and musculoskeletal disease spectra are associated with gradients of physical impairments. We examined a cardiovascular disease spectrum which consisted of hypertension, ischaemic heart disease and heart failure, and a musculoskeletal disease spectrum of lower back pain, osteoarthritis and rheumatoid arthritis. Using Medline, EMBASE and CINAHL databases, articles which had examined these morbidities and used either the SF-12 or SF-36 in general or primary care populations were selected; data was extracted independently by three reviewers. Study characteristics were described and the mean physical component summary scores of the SF-12 or SF-36 was analysed by disease, using random-effects meta-analysis. The association between disease and physical health (mean physical component summary scores) was assessed using multilevel meta-regression analysis, adjusting for age, health setting, country, disease definition and SF-12 or 36 format. From this search, 26 articles were identified, yielding 70 separate estimates of mean physical component summary scores across the morbidities from 14 different countries. For the selected conditions, pooled unadjusted mean physical component summary scores were: 44.4 for hypertension, 38.9 for ischaemic heart disease, 35.9 for heart failure, 39.5 for lower back pain, 36.0 for osteoarthritis and 36.5 for rheumatoid arthritis. The adjusted meta-regression showed mean physical component summary score difference for ischaemic heart disease of -4.6 (95\% confidence interval -6.0 to -3.2$)$ and heart failure $-7.5(-9.1$ to -5.9$)$ compared to the hypertension category. For osteoarthritis -4.2 ( -5.3 to -3.0$)$ and rheumatoid arthritis -3.9 ( -9.5 to 1.6$)$ compared to the lower back pain category. Our findings provide the benchmark norms for the differences in physical health within and between disease spectra. Improved characterisation of the relative impact of individual conditions on physical health will facilitate public health assessments of chronic diseases as well as assessments of interventions using functional patient-reported outcomes.
\end{abstract}

Keywords: Cardiovascular diseases, Chronic Disease, Musculoskeletal diseases, Physical health, Quality-of-Life

\footnotetext{
* Correspondence: j.a.prior@keele.ac.uk

${ }^{1}$ Research Institute for Primary Care and Health Sciences, Keele University, Staffordshire ST5 5BG, UK

Full list of author information is available at the end of the article
} 


\section{Introduction}

Research has shown the influence of specific chronic diseases on patients' self-reported health status and found the magnitude of this to vary by disease [1, 2]. For example, both Ischaemic Heart Disease (IHD) and Osteoarthritis (OA) will adversely impact on physical health, but the relative impact of these two diseases in a patient population may vary [3,4]. Chronic diseases often include conditions at differing stages of development, which means that each chronic disease is in fact a spectrum of conditions. IHD is only one example in a cardiovascular disease spectrum, ranging from hypertension to severe cardio or cerebrovascular conditions, which are linked by pathophysiology [5]. In contrast $\mathrm{OA}$ is just one example of a pain condition in a musculoskeletal disease spectrum, which can range from localised pain symptoms to more systemic conditions such as Rheumatoid Arthritis [6]. In this spectrum the links are based on the common symptom of pain, as opposed to shared pathophysiology.

For public health, the importance of this 'spectrum' approach is that it provides a population perspective of the range of conditions which may be associated with differing physical health impairments, with the implication that differing interventions may be required.

This conceptual approach of spectra is under-pinned by our previous clinical and epidemiological studies [7-9] and provides the opportunity to examine the concept of 'relative severity', i.e. how individual conditions influence health within the same chronic disease spectrum relative to one another [10]. This definition of 'relative severity' of different health conditions is based on previous GP focus groups, where the criteria for classifying severity were developed using clinical data and defined into four categories: i) chronicity and threat, ii) time course, iii) health care use, iv) impact on patients' Activities of Daily Living (ADL)). Following this, a further 118 GPs took part in a consensus study to agree the severity definitions for a total of 188 morbidities. These methods were then tested in both English and Dutch general practice populations $[8,9]$.

Our rationale to examine different conditions, ranked a priori based on their severity within a spectrum is based on the knowledge that the 'severity' of a health condition frequently influences its clinical management. By understanding the state of a given condition within a spectrum, this can provide additional insight into a particular outcome and subsequent clinical decisionmaking. Therefore, knowledge of severity of conditions on a population level can add to the information aiding treatment and management choices.

Over recent decades, the measurement of overall health and physical health impairment using standardised questionnaires has become routine as a basis for measuring disease-related outcomes and focused on obtaining patient- centred outcomes data in international research and clinical practice. The most commonly used of such general health and well-being measures in population-based studies are the SF-12 \& SF-36 health surveys [11]. The accumulation of such evidence provides the basis for benchmarking norms for the differences in physical health within and between chronic diseases. Synthesis of this evidence would provide population-based assessments of physical health for evaluation of healthcare resource allocation and the normative data that would be critical to interpreting such physical health data.

Whilst there is any number of spectra that could be tested under this hypothesis, the focus in this paper is on two spectra of common disease in populations, cardiovascular disease (CVD) and musculoskeletal disease (MSD) $[6,8]$. To make the hypothesis testable and feasible, we a priori selected three specific morbidities for each spectrum and based their order of severity classification on our previous research. For the CVD spectrum; we chose the common and linked morbidities of hypertension, Ischaemic Heart Disease (IHD) and Heart Failure (HF) [12]. For the MSD spectrum, we chose the morbidities for which pain symptoms are a common experience, Lower Back Pain (LBP), Osteoarthritis (OA) and Rheumatoid Arthritis (RA) [13]. Using the three stated examples for the CVD and MSD spectra, we undertook a systematic review to examine the current evidence on the physical health status of these conditions, measured using the SF12 or SF-36 [14, 15], in general populations or primary care populations. The objectives using systematic review and meta-analysis methods were; 1 ) to examine how physical health differs within a CVD and MSD spectrum and 2) to examine whether physical health differs between the two specified chronic disease spectrums.

\section{Methods}

A systematic review, meta-analysis and meta-regression of identified research articles were conducted. Medical literature databases were searched to identify articles which included study samples defined with at least one of six specified conditions (hypertension, IHD and HF; and LBP, OA and RA), and which had reported a physical health outcome in the general population or primary care population. Selection of articles was based on standardised inclusion and exclusion criteria. Initial comparisons of the mean PCS scores were made using meta-analysis; a meta-regression was used to examine pooled and adjusted estimates for each condition and compared within and between the two spectrums.

\section{Chronic disease spectra}

For CVD, the systematic review focused on hypertension, IHD and HF articles. Where an article included patients who had been defined as having IHD, angina or myocardial 
infarction (MI), all were defined within the IHD category. For MSD, the focus was on LBP, OA and RA articles. Within each spectra, use of the three conditions is justified for such examination based on their distinct severity and symptom profiles at a population level. Conditions were placed in a priori order of severity, based on previous clinical and validation studies in English and Dutch populations $[7,8]$ and the distinct spread of symptom experience for these conditions within their respective chronic diseases meant that conditions could be ordered from 'less severe' (i.e. hypertension for CVD and LBP for MSD) to those defined as 'moderately severe' (i.e. IHD for CVD and OA for MSD), and to 'most severe' (i.e. HF for CVD and RA for MSD).

\section{Article selection}

Standard search strategies were carried out in the three databases of Medline, EMBASE and CINAHL, using the National Health Service (NHS) evidence webpage (https://www.evidence.nhs.uk/). Selection of an article into the final review was based on inclusion criteria which included; (i) study samples being aged $\geq 18$ years, (ii) recruited either from the general population or primary care and (iii) defined as having one of the six study specified conditions of interest. Only observational studies were included in the review.

The primary measure of physical health for studies in this review was the Physical Component Summary (PCS) score from either the SF-12 or SF-36. Both the SF-12 \& SF-36 surveys form aggregate scores of general physical health, the PCS score and general mental health, the Mental Component Summary (MCS) score. These scores are normalised to a general US population mean of 50 (Standard Deviation (SD) 10), scores below 50 indicate worse physical or mental health than the 'average' US population [16]. The use of these summary scores across the selected articles allowed the comparison of different conditions in populations [17-20].

Exclusion criteria were (i) specifically sampling patients only aged 17 years or under, (ii) articles published pre-1990 (these SF surveys were developed from the late 1980s and not used prior to the 1990s [14]), (iii) related to a randomised control trial (RCT) design, or iv) nonEnglish language articles due to limited resources for translation. In articles including both baseline and follow-up longitudinal data from observational studies, only the baseline data was included into the analysis.

\section{Search and selection strategies}

This systematic review implemented nine search strategies in total, as a result of conducting three chronic disease specific searches ("cardiovascular", "musculoskeletal" and "chronic") in the three literature databases (Additional file 1: Table S1a-c). Each search strategy was based on 'exploded' Medical Subject Heading (MeSH) terms and individual keywords.

The selection of articles was based on; title screening, abstract screening, and then review of the full article, using a total of three reviewers (JAP, KPJ, UTK). Titles were screened by the first reviewer (JAP), and the list of abstracts for inclusion or exclusion generated. Two reviewers (UTK \& KPJ), blinded to the abstract selections of the first reviewer, completed the abstract selection by reviewing half the total number of abstracts each. Disagreements on inclusion or exclusion of articles were resolved using a triangulation process.

The full articles included in the review underwent structured data extraction. Each article could have examined the influence of several of the six specified conditions of interest. The mean PCS scores for each condition, and a measure of distribution around the mean; (Standard Deviation (SD)), were extracted. Other information extracted included: the lead author and publication year; sample size, along with their mean age (SD), the health care setting (general population or primary care), method of condition definition, samples' country and SF format used (SF-12 or SF-36). In the instances where an article was included in the review, but the required data were not reported, the corresponding author was contacted and the data requested directly.

\section{Data synthesis \& analysis}

Mean PCS scores for each condition were initially compared through meta-analysis and presented as forest plots. For each condition, articles were ordered by the region from which they came; Europe (subdivided into Northern, Eastern, Southern or Western Europe), North America or Asia. These forest plots provided a graphical representation of the mean PCS score by; i) article, ii) condition and iii) each chronic disease overall. This unadjusted analysis used a random-effects meta-analysis model. For IHD, where separate estimates for 'IHD only', 'angina' and 'MI' were given in a study, these were combined where appropriate.

Multilevel meta-regression [21] was used to compare the pooled mean PCS scores between the conditions. This method takes into account the potential clustering effects within studies examining more than one of the selected conditions (for example, patients in both the hypertension and heart failure condition categories).

A separate meta-regression was conducted for CVD and MSD to examine the within spectrum association with mean PCS score (reference categories were; hypertension for CVD \& LBP for MSD). Following that, a further meta-regression was conducted to examine the between spectra association with mean PCS score compared to the reference category (hypertension) mean PCS score. Difference in PCS scores from the reference category in each set 
of analysis were defined as a 'Minimal Clinically Importance Difference' (MCID) if the PCS score was 3 points or greater [22]. Meta-regressions were adjusted for age, health setting, country, method for defining condition and format of the SF survey. Each of these variables represents a potential source of variation in the SF estimate.

Each variable was dichotomised, these binary variables included; mean dataset age ( $\leq 59$ or $\geq 60$ years); health setting (general population or primary care); country (Europe or 'Rest of the world); method of condition definition (self-report or 'other method) and finally, whether the SF-12 or SF-36 had been used. Within spectrum metaregression was reported as i) unadjusted values, ii) adjusted for age and iii) adjusted for all other stated variables mentioned above. Between spectra meta-regression is only reported with adjustment for all stated variables. Analyses were performed using STATA/IC 12.1 for Windows and MLwiN v.2.22 [23].

\section{Results}

\section{Article selection}

From the total of 3,384 unique articles identified, after exclusion, 122 were reviewed in full. From these 122 articles, 20 met the inclusion criteria and an additional six articles were identified through the reference lists of the included 20. This process resulted in 26 articles finally being included in the systematic review (Fig. 1).

The 26 articles included in this review were from 14 different countries, incorporating a total of 70 estimates of mean PCS scores across the six specified conditions and for a total population of 43,840 individuals. For the CVD spectrum, this review identified 22 estimates for hypertension [4, 10, 24-36], 19 estimates for IHD [4, 10, 27, 33, 36, 37] and 12 for $\operatorname{HF}[10,27,36,38,39]$. CVD studies were predominantly from European countries, with several also from the US \& Asia. For the MSD spectrum, six mean PCS estimates for LBP [4, 10, 31, 40-42], seven for OA [3, 10, 31, 33, 41, 43] and four for RA [25, 44-46] were identified. MSD studies were predominantly from European countries, with several also from the US.

At the point of meta-analysis, IHD articles having examined more than one IHD sample (i.e. MI \& angina) were pooled. Therefore, a total of 64 estimates of mean PCS scores were finally used in the meta-analysis and meta-regression, 13 of which were categories as IHD, condensed from the original 19.

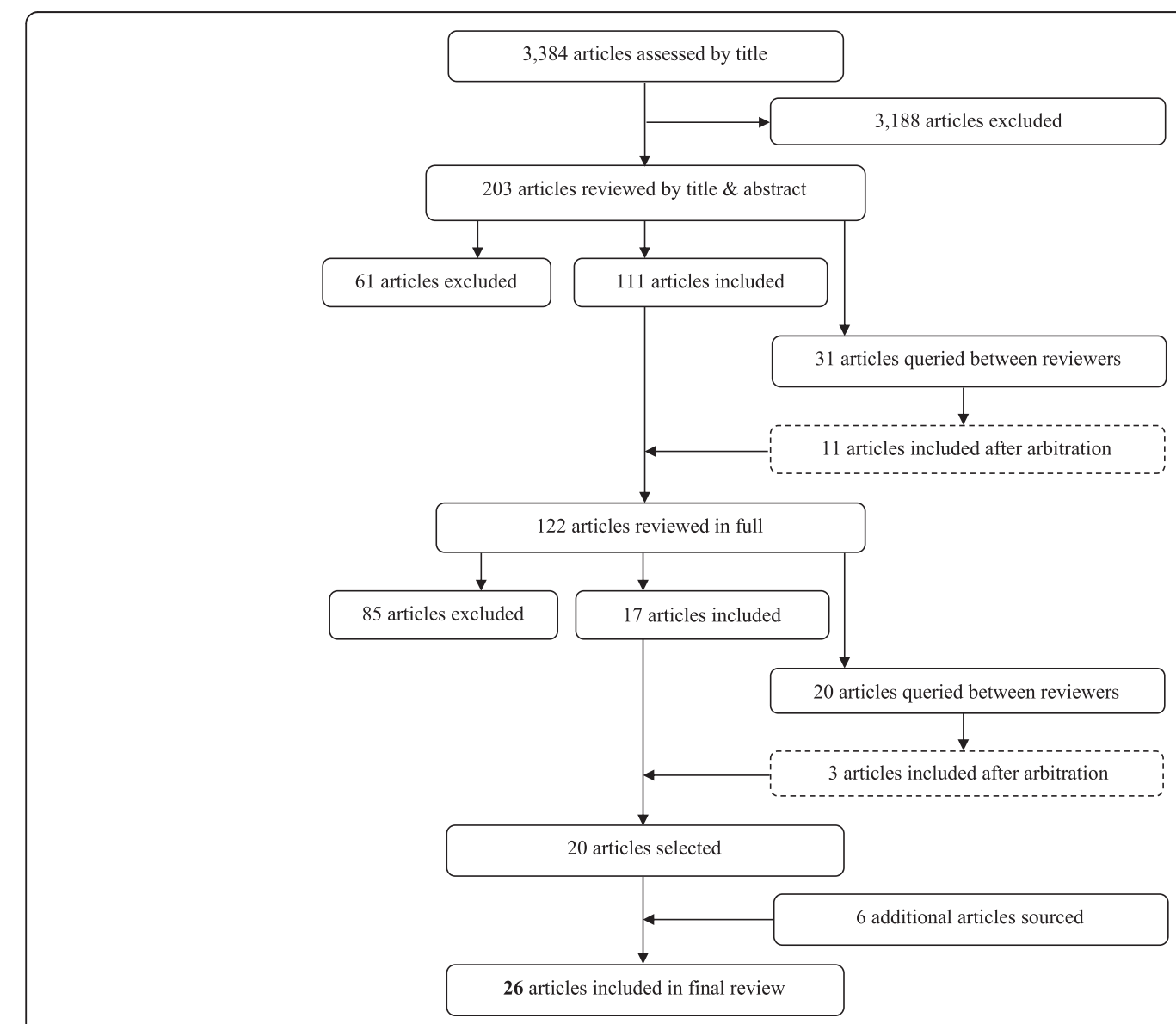

Fig. 1 Selection of studies for inclusion in review 
CVD spectrum and physical health

The 22 estimates of PCS scores in hypertension samples came from 15 articles in 12 countries, with a combined size of 27579. The mean ages of these samples ranged from 42.9-68.1 years, with just over half from the general population. The 19 estimates of PCS scores in IHD samples came from six articles in 11 countries with a combined size of 3641. Half of these came from the general population with mean ages ranging from $43.3-70.2$ years. For HF there were 12 estimates of PCS scores from five articles in eight countries with a combined sample of 1985. Mean ages of these samples ranged from 57.4-76.5 years, with two thirds from general population samples (Additional file 2: Tables S2a-c).

Estimates from the initial meta-analyses showed the following summary scores: for hypertension pooled mean PCS score was 44.4 (95\% CI 43.4 to 45.2); IHD was 38.9 (36.9 to 41.0) and for HF was 35.9 (34.1 to 37.6) (Fig. 2).

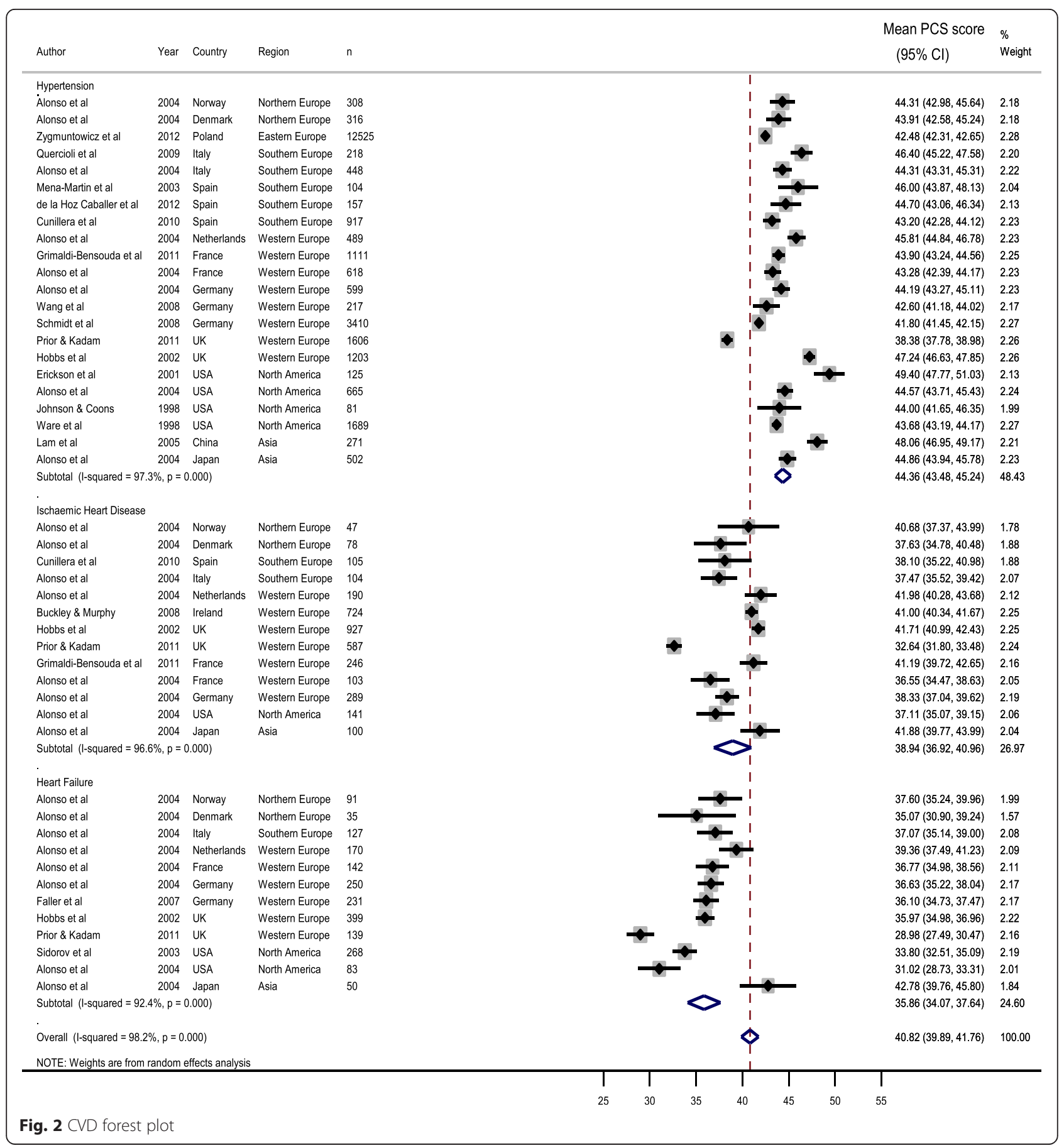




\section{Meta-regression of CVD studies}

The unadjusted meta-regression showed an association between increasing CVD severity and poorer physical health (Table 1). Compared to the US general population mean of 50, the unadjusted mean PCS score was six points lower for hypertension, 11 points lower for IHD, and 14 points lower for HF. When adjusted for age, differences between the CVD conditions remained, but did decrease in magnitude. With hypertension as the reference group, the age-adjusted pooled mean PCS score for both IHD (-4.6 (-5.9 to -3.2$)$ ) and for HF (-7.3 $(-9.1$ to -5.9$))$ were significantly lower. The final stage of adjustment for health setting, country, condition definition and SF-12 or 36 formats had minimal influence on these associations, which remained significant.

\section{MSD spectrum and physical health}

The six estimates of mean PCS scores for LBP were from separate articles from six different countries, with a combined size of 2433. Mean ages ranged from 49.981 years, with four drawn from primary care. There were seven estimates of mean PCS scores for OA from seven articles, in six different countries with a combined size of 7582. Mean ages ranged from 43.3-71.0 years, with all but one study conducted in primary care. Finally, the four estimates of mean PCS scores for RA came from four articles in three countries with a combined size of 2620. Three of the four were based in primary care and mean ages ranged from 53.9-61.3 years old (Additional file 2: Tables S2d-f).

Estimates from the initial meta-analyses showed the following summary scores: for LBP pooled mean PCS score was 39.4 (35.9 to 43.0); OA was 36.0 (33.3 to 38.6) and for RA was 36.5 (33.6 to 39.4) (Fig. 3).

\section{Meta-regression of MSD studies}

The unadjusted meta-regression showed similar associations of OA and RA having poorer physical health compared to the LBP category. Compared to the US average, the unadjusted mean PCS score was 10 points lower for LBP, 14 points lower for OA, and 13 points lower for RA. With LBP as the reference group, the age-adjusted pooled mean PCS score for both OA $(-4.2(-5.3$ to -3.1$))$ and RA $(-4.1(-7.9$ to -0.3$))$ was significantly lower. Further adjustment for health setting, country, condition definition and SF-12 or SF-36 format had minimal influence on the magnitude of associations with $\mathrm{OA}$, but the association for RA became non-significant (Table 1).

\section{Comparison between spectrums}

Compared to hypertension, the adjusted pooled mean PCS score for LBP was non-significantly lower by -1.7 ( -3.6 to 0.2$)$, whilst OA was significantly lower by -5.1 ( -6.9 to -3.3$)$ and RA significantly lower by -6.0 (-9.5 to -2.5$)$. The adjusted estimates of pooled PCS scores for hypertension and LBP were similar, as were those of IHD and OA, and for HF and RA (Table 1).

\section{Discussion}

\section{Overall findings}

This systematic review and meta-analysis provides population-based estimates of physical health limitations associated with cardiovascular and musculoskeletal diseases from international studies. For CVD, the gradient in associations from hypertension to IHD to HF, provide an indicative health status of populations and the potential change in physical health across the CVD spectrum as populations go from a single cardiovascular disease (such as hypertension) to more complex end-stage conditions such as heart failure. For the MSD spectrum, there was

Table 1 Comparison of pooled mean PCS scores between conditions

\begin{tabular}{|c|c|c|c|c|c|}
\hline \multirow[b]{2}{*}{$\begin{array}{l}\text { Condition } \\
\text { category }\end{array}$} & \multirow[b]{2}{*}{$\begin{array}{l}\text { Unadjusted Mean } \\
\text { PCS score (95\% CI) }\end{array}$} & \multicolumn{3}{|l|}{$\begin{array}{l}\text { Within spectrum } \\
\text { analysis }^{a}\end{array}$} & \multirow{2}{*}{$\begin{array}{l}\text { Between spectrum analysis }{ }^{a} \\
\text { Adjusted }{ }^{b} \text { difference in } \\
\text { mean PCS score }(95 \% \mathrm{Cl} \text { ) }\end{array}$} \\
\hline & & $\begin{array}{l}\text { Unadjusted difference in } \\
\text { mean PCS score }(95 \% \text { Cl) }\end{array}$ & $\begin{array}{l}\text { Age adjusted difference in } \\
\text { mean PCS score }(95 \% \mathrm{Cl})\end{array}$ & $\begin{array}{l}\text { Adjusted }{ }^{b} \text { difference in } \\
\text { mean PCS score }(95 \% \text { Cl) }\end{array}$ & \\
\hline \multicolumn{6}{|c|}{ Cardiovascular diseases } \\
\hline Hypertension & 44.4 (43.5 to 45.2$)$ & Ref & Ref & Ref & Ref \\
\hline $\begin{array}{l}\text { Ischaemic Heart } \\
\text { Disease }\end{array}$ & 38.9 (36.9 to 41.0$)$ & $-5.3(-6.4$ to -4.1$)$ & $-4.6(-5.9$ to -3.2$)$ & $-4.6(-6.0$ to -3.2$)$ & $-4.8(-6.2$ to -3.5$)$ \\
\hline Heart Failure & 35.9 (34.1 to 37.6$)$ & $-8.2(-9.5$ to -7.0$)$ & $-7.3(-8.9$ to -5.7$)$ & $-7.5(-9.1$ to -5.9$)$ & $-7.4(-8.9$ to -5.9$)$ \\
\hline \multicolumn{6}{|c|}{ Musculoskeletal diseases } \\
\hline $\begin{array}{l}\text { Lower Back } \\
\text { Pain }\end{array}$ & 39.4 (35.9 to 43.0$)$ & Ref & Ref & Ref & $-1.7(-3.6$ to 0.2$)$ \\
\hline Osteoarthritis & 36.0 (33.3 to 38.6) & $-4.3(-5.4$ to -3.2$)$ & $-4.2(-5.3$ to -3.1$)$ & $-4.2(-5.3$ to -3.0$)$ & $-5.1(-6.9$ to -3.3$)$ \\
\hline $\begin{array}{l}\text { Rheumatoid } \\
\text { Arthritis }\end{array}$ & 36.5 (33.6 to 39.4$)$ & $-2.7(-4.3$ to -1.1$)$ & $-4.1(-7.9$ to -0.3$)$ & $-3.9(-9.5$ to 1.6$)$ & $-6.0(-9.5$ to -2.5$)$ \\
\hline
\end{tabular}

accounting for clustering within studies using multilevel meta-regression

${ }^{\mathrm{b}}$ Adjusted for: age, health setting, location, method of disease definition \& SF-12 or SF-36 format 


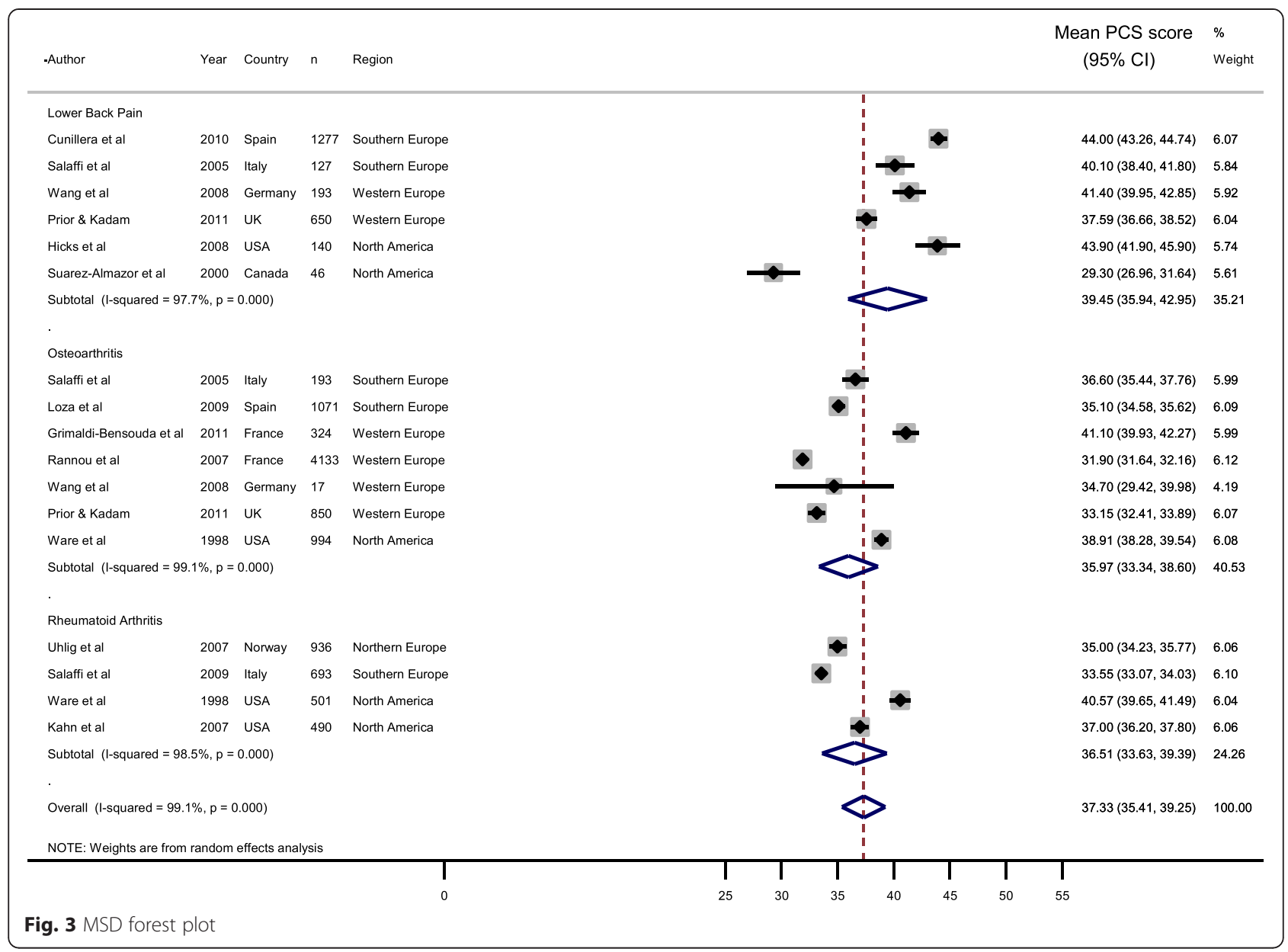

less of a gradient in the three chosen conditions which indicates that associated poor health might not develop across the pain-spectrum conditions as hypothesised.

Within the CVD spectrum, the mean PCS score estimates of hypertension and IHD were comparable to those of the same disease groups from US normative disease group data. Our estimates for hypertension 44.4 and for IHD 38.9, were comparable to those reported in the derived SF-12 US normative median values of 45.5 and 38.1 respectively [47]. Such similarity of these crude PCS scores suggests our estimates provide an accurate baseline from which to consider the adjusted differences between conditions.

After adjustment for age and other study-design factors, the differences within the selected CVD spectrum were greater than 3 points, which can be considered a minimal clinically important difference [22, 48]. Such differences provide the public health estimation of physical health impairments within the CVD spectrum as these related conditions develop. In current public health approaches, interventions are tailored to the CVD spectrum for the reduction in mortality outcomes $[49,50]$. Therefore, such an existing framework could be applied to the characterisation of relative impact of chronic diseases on physical health. This will facilitate public health assessments of chronic disease progression as well as assessments of interventions using functional patient-reported outcomes. For example, population level benchmark norms could be used to produce clinical guidance on when interventions to improve physical health should be introduced during the course of a progressing chronic disease, such as CVD.

Whilst all three selected MSD were associated with poorer physical health compared to the general US population, the relative differences between the conditions were less distinct than the CVD spectrum. It is arguable here that public health approaches to these types of MSD need to focus on the pathology of the pain condition as opposed to quality of life in such populations [51-53]. Though the relative adjusted difference was deemed clinically important and significant for OA and RA (4 points lower) compared to LBP, crude estimates were not comparable to US disease specific norms. Our crude estimate for LBP was much poorer (10 points) than mean scores determined for the same disease group from normative US data (39.4 vs. 48.6 respectively). Estimates for OA \& 
RA were also poorer than normative disease specific data. However, we did observe a similar impact on mean PCS score estimates for OA \& RA ( 36.0 \& 36.5 respectively) which was also shown by the US normative disease specific data (39.0 \& 40.9 respectively) [47]. Here the findings suggest a severe, but similar influence of the MSD conditions on physical health, but do not support the MSD gradient.

In public health terms, the importance of these findings here is that for this CVD spectrum we have quantified a gradient of physical health in different conditions. Though it could be argued that comorbidity is contributing to such poor physical health, it still remains that populations with serious CVD such as heart failure will have poorer health, no matter the direct cause. However, for MSD, it may be the experience of any MSD condition that is important and not necessarily what type.

The findings between chronic disease spectra suggest that the associations with poor physical health status can be similar in populations that might experience CVD or MSD. The adjusted estimate of physical health score for LBP was not statistically different from hypertension, IHD was equivalent to OA, and HF was similar to RA. Such results give additional support to our constructed spectra, as results are comparable across the 'less', 'moderately' and 'most' severe conditions displaying similar impacts on physical health. In public health terms, the importance of these comparable findings is the suggestion that, on a population level, any CVD and MSD conditions of a similar 'severity level' may be important in the influence on physical health and not necessarily the specific type of condition.

\section{Strengths and limitations}

This systematic review and meta-analysis identified the key international studies that had investigated the association between chronic disease and physical health measured using a standardised instrument. This was achieved by the a priori test of relative severity, ordering diseases within the same chronic disease spectrum. The selection of the two spectra, both formed from common conditions, provides the comparison of physical health estimates and the practical approach to devising comparisons within and between different chronic diseases.

In using data drawn from international studies, the caveat is that heterogeneity for the selected condition categories might be the partial explanation for some of the differences identified, despite the adjustment for the study design and setting. Whilst, specific conditions such as heart failure, ischaemic heart disease, osteoarthritis and rheumatoid arthritis have defined diagnostic criteria [54-57], conditions such as hypertension and lower back pain criteria might differ. The scope of the review was international and most studies were of an appropriately large sample size, however the exclusion of articles not written in English, might have introduced selection issues. It could be argued that the MSD examples had reduced power to detect the range of physical impairments because of the small number of studies identified. Finally, though each condition in the CVD or the MSD spectrum were indicators of the likely physical impairment, the analyses did not account for comorbidity, other than adjusting by age as a proxy marker. Conditions such as heart failure or rheumatoid arthritis often accrue comorbidity as a result of age and complication, and the physical impairment therefore may in part be a reflection of the index HF or RA, or also any associated comorbidity.

\section{Conclusions}

Our systematic review and meta-analysis describes the relative physical limitations associated with spectra of cardiovascular and musculoskeletal diseases. The findings provide benchmark norms for the differences in physical health both within and between diseases. Improved characterisation of the relative impact of health conditions on physical health will facilitate public health assessments of chronic disease, as well as population-based assessments of clinical interventions using functional outcomes which are meaningful to patients.

\section{Additional files}

Additional file 1: Table S1a. Cardiovascular disease search strategy Table S1b. Musculoskeletal disease search strategy. Table S1c. Chronic disease search strategy.

Additional file 2: Table 2a. Hypertension articles $(n=22)$. Table S2b. Ischaemic heart disease articles $(n=19)$. Table S2c. Heart failure articles $(n=12)$. Table S2d. Lower Back Pain articles $(n=6)$. Table S2e.

Osteoarthritis articles $(n=7)$. Table S2f. Rheumatoid arthritis articles $(n=4)$.

\section{Abbreviations}

Cl: Confidence Interval; CVD: Cardiovascular Disease; HF: Heart Failure; IHD: Ischaemic Heart Disease; LBP: Lower Back Pain; MCID: Minimal Clinically Importance Difference; MCS: Mental Component Summary; MeSH: Medical Subject Heading; MI: Myocardial Infarction; MSD: Musculoskeletal Disease; NHS: National Health Service; NIHR: National Institute for Health Research; OA: Osteoarthritis; PCS: Physical Component Summary; RA: Rheumatoid Arthritis; RCT: Randomised Control Trial; SD: Standard Deviation; SE: Standard Error; UK: United Kingdom; US: United States.

\section{Competing interests}

The authors declare that they have no competing interests.

\section{Author's contribution}

JAP was involved in every aspect of the systematic review, designing the methods, constructing and conducting searches, analysis and writing. KJP \& UTK oversaw all aspects of the review, but specifically KJP advised on analysis and UTK proposed initial research idea. All authors were involved in article selection, writing and read and approved the final manuscript.

\section{Acknowledgements}

We are grateful to authors who provided additional data on request. UTK was funded by a National Institute for Health Research (NIHR) Post-Doctoral Fellowship (grant no. PAS/PDA/03/07/035) and by a Royal Society 
International Short Visit grant and the West Midlands Advantage scheme. The study sponsors had no role in; study design, in the collection, analysis, and interpretation of data; in the writing of the report; or in the decision to submit the paper for publication. The views and opinions expressed therein are those of the authors and do not necessarily reflect those of the NIHR (UK).

\section{Author details}

${ }^{1}$ Research Institute for Primary Care and Health Sciences, Keele University, Staffordshire ST5 5BG, UK. ${ }^{2}$ Health Services Research Unit, Keele University, Keele, UK.

\section{Received: 16 January 2015 Accepted: 15 May 2015}

Published online: 30 May 2015

\section{References}

1. Sprangers MAG, de Regt EB, Andries F, van Agt HME, Bijl RV, de Boer JB, et al. Which chronic conditions are associated with better or poorer quality of life? J Clin Epidemiol. 2000;53(9):895-907.

2. Bayliss M, Rendas-Baum R, White M, Maruish M, Bjorner J, Tunis S. Health-related quality of life (HRQL) for individuals with self-reported chronic physical and/or mental health conditions: panel survey of an adult sample in the United States. HQLO. 2012;10(1):154.

3. Loza E, Lopez-Gomez JM, Abasolo L, Maese J, Carmona L, Batlle-Gualda E, et al. Economic burden of knee and hip osteoarthritis in Spain. Arthritis Rheum. 2009;61(2):158-65.

4. Cunillera O, Tresserras R, Rajmil L, Vilagut G, Brugulat P, Herdman M, et al. Discriminative capacity of the EQ-5D, SF-6D, and SF-12 as measures of health status in population health survey. Qual Life Res. 2010;19(6):853-64.

5. Bardage C, Isacson DG. Hypertension and health-related quality of life. an epidemiological study in Sweden. J Clin Epidemiol. 2001;54(2):172-81.

6. Jordan KP, Jöud A, Bergknut C, Croft P, Edwards JJ, Peat G, Petersson IF, Turkiewicz A, Wilkie R, Englund M: International comparisons of the consultation prevalence of musculoskeletal conditions using populationbased healthcare data from England and Sweden. Ann Rheum Dis. 2014:73(1):212-8

7. Kadam UT, Jordan K, Croft PR. A comparison of two consensus methods for classifying morbidities in a single professional group showed the same outcomes. J Clin Epidemiol. 2006;59(0895-4356; 11):1169-73.

8. Kadam UT, Schellevis FG, van der Windt DA, de Vet HC, Bouter LM, Croft PR. Morbidity severity classifying routine consultations from English and Dutch general practice indicated physical health status. J Clin Epidemiol. 2008;61(4):386-93.

9. Kadam UT, Schellevis FG, Lewis M, van der Windt DA, de Vet HC, Bouter LM, et al. Does age modify the relationship between morbidity severity and physical health in English and Dutch family practice populations? Qual Life Res. 2009;18(2):209-20.

10. Prior JA, Kadam UT. Cardiovascular disease and musculoskeletal disorder labels in family practice acted as markers of physical health severity. J Clin Epidemiol. 2011;64(5):547-55.

11. Garratt A, Schmidt L, Mackintosh A, Fitzpatrick R. Quality of life measurement: bibliographic study of patient assessed health outcome measures. BMJ. 2002;324(7351):1417.

12. Levy D, Larson MG, Vasan RS, Kannel WB,Ho KK. The Progression From Hypertension to Congestive Heart Failure. JAMA. 1996;275(20):1557-1562. doi:10.1001/jama.1996.03530440037034

13. Woolf AD, Åkesson K. Can we reduce the burden of musculoskeletal conditions? The European action towards better musculoskeletal health. Best Pract Res Cl Rh. 2007;21(1):1-3.

14. Ware Jr JE, Sherbourne CD. The MOS 36-item short-form health survey (SF-36). I. Conceptual framework and item selection. Med Care. 1992;30(6):473-83.

15. Ware Jr J, Kosinski M, Keller SD. A 12-item short-form health survey: construction of scales and preliminary tests of reliability and validity. Med Care. 1996;34(3):220-33.

16. Ware Jr JE, Kosinski M, Bayliss MS, McHorney CA, Rogers WH, Raczek A. Comparison of methods for the scoring and statistical analysis of SF-36 health profile and summary measures: summary of results from the medical outcomes study. Med Care. 1995;33(4 Suppl):AS264-79.

17. Cote I, Gregoire JP, Moisan J, Chabot I. Quality of life in hypertension: the SF-12 compared to the SF-36. Can J Clin Pharmacol. 2004;11(2):e232-8.

18. Jenkinson CRIS, Jenkinson DAMI, Shepperd SASH, Richard LAYT, Petersen $\mathrm{SOPH}$. Evaluation of treatment for congestive heart failure in patients aged
60 years and older using generic measures of health status (SF-36 and COOP charts). Age Ageing. 1997;26(1):7-13.

19. Mols F, Pelle AJ, Kupper N. Normative data of the SF-12 health survey with validation using postmyocardial infarction patients in the Dutch population. Qual Life Res. 2009;18(4):403-14.

20. Gandhi SK, Salmon JW, Zhao SZ, Lambert BL, Gore PR, Conrad K. Psychometric evaluation of the 12-item short-form health survey (SF-12) in osteoarthritis and rheumatoid arthritis clinical trials. Clin Ther. 2001;23(7):1080-98.

21. Goldstein H, Yang M, Omar R, Turner R, Thompson S. Meta-analysis using multilevel models with an application to the study of class size effects. J R Stat Soc: Ser C: Appl Stat. 2000;49(3):399-412.

22. Samsa G, Edelman D, Rothman ML, Williams GR, Lipscomb J, Matchar D. Determining clinically important differences in health status measures: a general approach with illustration to the health utilities index mark II. Pharmacoeconomics. 1999;15(2):141-55.

23. Rasbash J, Steele F, Browne WJ, Goldstein H: A user's guide to MLwiN version 2.0. Printed in the United Kingdom: University of Bristol; 2005.

24. Johnson JA, Pickard AS. Comparison of the EQ-5D and SF-12 health surveys in a general population survey in Alberta, Canada. Med Care. 2000;38(1):115-21.

25. Ware JE, Kosinski M, Keller SD. SF-36 physical and mental health summary scales: a User's manual. Boston, MA: The Health Institute; 1994

26. Erickson SR, Williams BC, Gruppen LD. Perceived symptoms and health-related quality of life reported by uncomplicated hypertensive patients compared to normal controls. J Hum Hypertens. 2001;15(8):539-48.

27. Hobbs FD, Kenkre JE, Roalfe AK, Davis RC, Hare R, Davies MK. Impact of heart failure and left ventricular systolic dysfunction on quality of life: a cross-sectional study comparing common chronic cardiac and medical disorders and a representative adult population. Eur Heart J. 2002;23(23):1867-76.

28. Mena-Martin FJ, Martin-Escudero JC, Simal-Blanco F, Carretero-Ares JL, Arzua-Mouronte D, Herreros-Fernandez V. Health-related quality of life of subjects with known and unknown hypertension: results from the population-based Hortega study. J Hypertens. 2003;21(7):1283-9.

29. Lam CLK, Tse EYY, Gandek B, Fong DYT. The SF-36 summary scales were valid, reliable, and equivalent in a Chinese population. J Clin Epidemiol. 2005;58(8):815-22.

30. Schmidt AC, Bramlage P, Limberg R, Kreutz R. Quality of life in hypertension management using olmesartan in primary care. Expert Opin Pharmacother. 2008;9(10):1641-53.

31. Wang HM, Beyer M, Gensichen J, Gerlach FM. Health-related quality of life among general practice patients with differing chronic diseases in Germany: cross sectional survey. BMC Public Health. 2008;8(1471-2458):246.

32. Quercioli C, Messina G, Barbini E, Carriero G, Fani M, Nante N. Importance of sociodemographic and morbidity aspects in measuring health-related quality of life: performances of three tools: comparison of three questionnaire scores. J Health Econ. 2009;10(4):389-97.

33. Grimaldi-Bensouda L, Begaud B, Lert F, Rouillon F, Massol J, Guillemot D, et al. Benchmarking the burden of 100 diseases: results of a nationwide representative survey within general practices. BMJ Open. 2011;1(2):e000215. 2011-000215. Print 2011.

34. de la Hoz Caballer B, Rodriguez M, Fraj J, Cerecedo I, Antolin-Amerigo D, Colas C. Allergic rhinitis and its impact on work productivity in primary care practice and a comparison with other common diseases: the cross-sectional study to evAluate work productivity in allergic rhinitis compared with other common dlseases (CAPRI) study. Am J Rhinol Allergy. 2012;26(5):390-4.

35. Zygmuntowicz M, Owczarek A, Elibol A, Chudek J. Comorbidities and the quality of life in hypertensive patients. Pol Arch Med Wewn. 2012;122(7-8):333-40.

36. Alonso J, Ferrer M, Gandek B, Ware Jr JE, Aaronson NK, Mosconi P, et al. Health-related quality of life associated with chronic conditions in eight countries: results from the International Quality of Life Assessment (IQOLA) project. Qual Life Res. 2004;13(2):283-98.

37. Buckley B, Murphy AW. Do patients with angina alone have a more benign prognosis than patients with a history of acute myocardial infarction, revascularisation or both? Findings from a community cohort study. Heart. 2009;95(6):461-7.

38. Sidorov J, Shull RD, Girolami S, Mensch D. Use of the short form 36 in a primary care based disease management program for patients with congestive heart failure. Dis Manag. 2003;6(2):111-7.

39. Faller H, Stork S, Schowalter M, Steinbuchel T, Wollner V, Ertl G, et al. Is health-related quality of life an independent predictor of survival in patients with chronic heart failure? J Psychosom Res. 2007;63(5):533-8. 
40. Suarez-Almazor ME, Kendall C, Johnson JA, Skeith K, Vincent D. Use of health status measures in patients with low back pain in clinical settings. Comparison of specific, generic and preference-based instruments. Rheumatology. 2000;39(7):783-90.

41. Salaffi F, De Angelis R, Stancati A, Grassi W, Pain M, Prevalence IG. Health-related quality of life in multiple musculoskeletal conditions: a cross-sectional population based epidemiological study. II. The MAPPING study. Clin Experimental Rheumatol. 2005:23(6):829-39.

42. Hicks GE, Gaines JM, Shardell M, Simonsick EM. Associations of back and leg pain with health status and functional capacity of older adults: findings from the retirement community back pain study. Arthritis Rheum. 2008:59(9):1306-13

43. Rannou F, Boutron I, Jardinaud-Lopez M, Meric G, Revel M, Fermanian J, et al. Should aggregate scores of the medical outcomes study 36 -item short form health survey be used to assess quality of life in knee and hip osteoarthritis? a national survey in primary care. Osteoarthritis Cartilage. 2007;15(9):1013-8.

44. Kahn KL, MacLean CH, Liu H, Rubenstein LZ, Wong AL, Harker JO, et al. The complexity of care for patients with rheumatoid arthritis: metrics for better understanding chronic disease care. Med Care. 2007:45(1):55-65.

45. Uhlig T, Loge JH, Kristiansen IS, Kvien TK. Quantification of reduced health-related quality of life in patients with rheumatoid arthritis compared to the general population. J Rheumatol. 2007;34(6):1241-7.

46. Salaffi F, Sarzi-Puttini P, Girolimetti R, Atzeni F, Gasparini S, Grassi W. Health-related quality of life in fibromyalgia patients: a comparison with rheumatoid arthritis patients and the general population using the SF-36 health survey. Clin Exp Rheumatol. 2009;27(5):S67-74.

47. Ware Jr JE, Kosinski M, Turner-Bowker DM, Gandek B. User's Manual for the SF-12v2 ${ }^{\circledast}$ Health Survey With a Supplement Documenting SF-12 ${ }^{\circledR}$ Health Survey) Lincoln, Rl: QualityMetric Incorporated, 2002.

48. Frendl DM, Ware Jr JE. Patient-reported functional health and well-being outcomes with drug therapy: a systematic review of randomized trials using the SF-36 health survey. Med Care. 2014;52(5):439-45.

49. Barton P, Andronis L, Briggs A, McPherson K, Capewell S. Effectiveness and cost effectiveness of cardiovascular disease prevention in whole populations: modelling study. BMJ. 2011;343:d4044

50. Ahern R, Lozano R, Naghavi M, Foreman K, Gakidou E, Murray C. Improving the public health utility of global cardiovascular mortality data: the rise of ischemic heart disease. Popul Health Metr. 2011;9(1):8.

51. Morone NE, Karp JF, Lynch CS, Bost JE, El Khoudary SR, Weiner DK. Impact of chronic musculoskeletal pathology on older adults: a study of differences between knee OA and low back pain. Pain Med. 2009;10(4):693-701.

52. Huijnen IPJ, Verbunt JA, Peters ML, Delespaul P, Kindermans HPJ, Roelofs J, et al. Do depression and pain intensity interfere with physical activity in daily life in patients with chronic low back pain? Pain. 2010;150(1):161-6.

53. Staud R. Evidence for shared pain mechanisms in osteoarthritis, low back pain, and fibromyalgia. Curr Rheumatol Rep. 2011:13(6):513-20.

54. McMurray JJ, Adamopoulos S, Anker SD, Auricchio A, Bohm M, Dickstein K, et al. ESC guidelines for the diagnosis and treatment of acute and chronic heart failure 2012: the task force for the diagnosis and treatment of acute and chronic heart failure 2012 of the European society of cardiology. Developed in collaboration with the heart failure association (HFA) of the ESC. Eur J Heart Fail. 2012;14(8):803-69.

55. Qaseem A, Fihn SD, Williams S, Dallas P, Owens DK, Shekelle $P$, et al. Diagnosis of stable ischemic heart disease: summary of a clinical practice guideline from the American college of physicians/american college of cardiology foundation/american heart association/american association for thoracic surgery/preventive cardiovascular nurses association/society of thoracic surgeons. Ann Intern Med. 2012;157(10):729-34.

56. Zhang W, Doherty M, Peat G, Bierma-Zeinstra MA, Arden NK, Bresnihan B, et al. EULAR evidence-based recommendations for the diagnosis of knee osteoarthritis. Ann Rheum Dis. 2010;69(3):483-9.

57. Aletaha D, Neogi T, Silman AJ, Funovits J, Felson DT, Bingham CO, et al. Rheumatoid arthritis classification criteria: an American college of rheumatology/European league against rheumatism collaborative initiative. Arthritis Rheum. 2010;62(9):2569-81

\section{Submit your next manuscript to BioMed Central and take full advantage of:}

- Convenient online submission

- Thorough peer review

- No space constraints or color figure charges

- Immediate publication on acceptance

- Inclusion in PubMed, CAS, Scopus and Google Scholar

- Research which is freely available for redistribution 